\title{
EXPERIMENTAL EVALUATION OF XENODIAGNOSIS TO DETECT TRYPANOSOMES AT LOW PARASITAEMIA LEVELS IN INFECTED HOSTS
}

\author{
WOMBOU TOUKAM C.M.*, SOLANO P.*,**, BENGALY Z.*, JAMONNEAU V.*,** \& BUCHETON B.*,**
}

\section{Summary:}

In Human African Trypanosomosis (HAT) endemic areas, there are a number of subjects that are positive to serological tests but in whom trypanosomes are difficult to detect with the available parasitological tests. In most cases and particularly in West Africa, these subjects remain untreated, thus posing a fundamental problem both at the individual level (because of a possible lethal evolution of the disease) and at the epidemiological level (since they are potential reservoirs of trypanosomes). Xenodiagnosis may constitute an alternative for this type of cases. The objective of this study was to update the use of xenodiagnosis to detect trypanosomes in infected host characterized by low parasitaemia levels. This was carried out experimentally by infecting cattle and pigs with Trypanosoma congolense and T. brucei gambiense respectively, and by feeding tsetse flies (Glossina morsitans submorsitans and G. palpalis gambiensis, from the CIRDES colonies) on these animals at a time when the observed blood parasitaemia were low or undetectable by the classical microscopic parasitological tests used for the monitoring of infected animals. Our results showed that: i) the G. p. gambiensis colony at CIRDES could not be infected with the $T$. b. gambiense stocks used; ii) midgut infections of G. m. submorsitans were observed with both $T$. congolense and T. b. gambiense; iii) xenodiagnosis remains positive even at very low blood parasitaemia for both T. congolense and T. b. gambiense; and iv) to implement T. b. gambiense xenodiagnosis, batches of 20 G. m. submorsitans should be dissected two days after the infective meal. These results constitute a first step toward a possible implementation of xenodiagnosis to better characterize the parasitological status of seropositive individuals and the modalities of parasite transmission in HAT foci.

KEY WORDS: xenodiagnosis, experimental evaluation, HAT, tsetse, trypanosome, parasitaemia.

\section{INTRODUCTION}

H uman African Trypanosomosis (HAT) is a parasitic disease caused by two sub-species of trypanosomes: Trypanosoma brucei (T. b.) gambiense and T. b. rodhesiense. T. b. gambiense,

\footnotetext{
* Centre international de recherche-développement sur l'élevage en zone subhumide (CIRDES), 01 BP 454 Bobo-Dioulasso 01, Burkina Faso. ** Institut de recherche pour le développement (IRD), Unité mixte de recherche IRD-CIRAD INTERTRYP, Campus international de Baillarguet, Montpellier, France.

Correspondence: Philippe Solano, Institut de recherche pour le développement, Unité mixte de recherche IRD-CIRAD 177, Campus international de Baillarguet, 34398 Montpellier Cedex 5, France. E-mail: philippe.solano@ird.fr
}

Résumé : ÉVALUATION EXPÉRIMENTALE DU XÉNODIAGNOSTIC POUR DÉTECTER LES TRYPANOSOMES CHEZ L'HÔTE INFECTÉ LORS DE PARASITÉMIES FAIBLES En zone d'endémie de la trypanosomose humaine africaine (THA), il existe des suspects positifs en sérologie chez lesquels les trypanosomes sont difficilement détectés en utilisant les tests de diagnostic parasitologique disponibles sur le terrain. Dans la plupart des cas, particulièrement en Afrique de l'Ouest, ces sujets ne sont pas traités, posant ainsi un problème fondamental à la fois au niveau individuel (à cause d'une possible évolution mortelle de la maladie) et au niveau épidémiologique (puisqu'ils sont de potentiels réservoirs de trypanosomes). L'objectif de notre étude était d'actualiser I'utilisation du xénodiagnostic pour détecter les trypanosomes chez des hôtes infectés caractérisés par de faibles parasitémies. Ceci a été fait expérimentalement en infectant des animaux, bovins et porcs, par Trypanosoma congolense et $\mathrm{T}$. brucei gambiense respectivement, sur lesquels des glossines (Glossina morsitans submorsitans et $\mathrm{G}$. palpalis gambiensis) de l'élevage du CIRDES étaient nourries lors de parasitémies faibles ou indétectables par des tests parasitologiques microscopiques classiques utilisés pour le suivi des animaux infectés. Nos résultats ont montré que : i) la colonie de G. p. gambiensis du CIRDES n'a pas pu être infectée par T. b. gambiense ; ii) l'infection de l'intestin moyen des G. m. submorsitans a été observée à la fois avec T. congolense et T. b. gambiense; iii) le xénodiagnostic demeure positif même à de très faibles parasitémies; et iv) pour mettre en œuvre ce xénodiagnostic, des lots de 20 glossines (G. m. submorsitans) peuvent être disséqués deux jours après le repas infectant. Ces résultats constituent une première étape vers une possible mise en œuvre du xénodiagnostic afin de mieux caractériser le statut parasitologique des individus séropositifs et les modalités de transmission du parasite dans les foyers de THA.

MOTS-CLÉS : xénodiagnostic, évaluation expérimentale, THA, glossine, trypanosome, parasitémie. 
fatal reactive encephalopathy in 5-10\% of cases), diagnostic is of crucial importance. For these reasons, mass screening of the population is usually performed by the Card Agglutination Test for Trypanosomosis (CATT), and parasitological tests, such as the miniAnion Exchange Centrifugation Test (m-AECT) or the Buffy Coat Technique (BCT), are then carried out on positive subjects to confirm infection (Jamonneau et al., 2004).

Because in T. b. gambiense HAT blood parasitaemia is often very low, the parasitological test used in the frame of medical surveys lack sensitivity. Thus, the parasitological status of a number of subject positive to serological tests but negative in parasitology is currently unknown although increasing data, such as the detection of parasite DNA by different PCR techniques, indicate that at least some of them could be asymptomatic carriers of parasite (Solano et al., 2002; Jamonneau et al., 2004; Koffi et al., 2006; Kaboré et al., 2011). A better parasitological characterization of these seropositive subjects, particularly to know if they can act as a parasite reservoir for tsetse flies is thus of crucial importance to improve control strategies by national control programs. Xenodiagnosis, which consists in detecting the parasite through the dissection of its arthropod vector, after having fed it on patients, is considered as one of the most sensitive parasitological tools, and has already been used in the past for sleeping sickness (Frézil, 1971).

In the present study, our objective was to revisit the possible contribution of xenodiagnosis to HAT diagnosis and to evaluate its sensitivity, by feeding tsetse flies on animals infected experimentally by different trypanosome species at time when blood parasitaemia were low or undetectable by classical parasitological tests.

\section{MATERIALS AND METHODS}

The experimental protocol received the agreement of the scientific ethics committee of CIRDES for animal care and the use of animals for research purposes.

\section{TRYPANOSOMES}

Two strains of trypanosomes were used in this experiment: a Trypanosoma congolense IL 1180 stabilate, originating from Serengeti in Tanzania, and an isolate of Trypanosoma brucei gambiense was used in the experimental infection of pig (isolate B4/F303). This isolate of $T$. $b$. gambiense had been isolated between 2000 and 2004 by rodent inoculation from HAT patients detected in the sleeping sickness focus of Bonon, Côte d'Ivoire, and kept in the cryotheque of IRD/CIRDES.
Cryostabilates of these strains were reactivated in mice prior the experimental infections.

\section{TSETSE FLIES}

A maximum of 72 hours old teneral males and females Glossina morsitans submorsitans and Glossina palpalis gambiensis reared at the Centre International de Recherche-Développement sur l'Élevage en Zone Subhumide (CIRDES) insectarium were used. G. $m$. submorsitans flies were fed on infected cows and pig whereas G. p. gambiensis flies were fed on infected pig only.

\section{ANIMALS}

Two crossbred zebu cows and one five-month old male pig of local race were used in these experiments. Upon arrival, they were dewormed with Veriben ${ }^{\circledR}$ and treated with oxytetracycline $5 \%$ at recommended dosage. Cows and pig were further kept on different insecticide impregnated net box within a wire-netting surrounding wall for pigs and simple surrounding wall for cows to prevent contact with other flies or other haematophagous insects.

\section{EXPERIMENTAL DESIGN}

- Reactivation of stabilates

NMRI mice previously immunosuppressed with cyclophosphamide (Endoxan ${ }^{\circledR}, 300 \mathrm{mg} / \mathrm{kg}$ ), were injected intraperitoneally with $0.3 \mathrm{ml}$ of cryostabilate containing at least $32 \times 10^{6}$ trypanosomes per millilitre (tryp/ml). Immuno-suppression was maintained using cyclophosphamide every five days. The parasitaemia of each mouse was measured daily using the matching method of Herbert \& Lumsden (1976).

- Experimental infection of animals

Cows: after the reactivation of parasite strains, cows were intraveinously injected with $1 \mathrm{ml}$ of diluted mice blood (in phosphate saline glucose) containing a final concentration of $10^{3} \mathrm{tryp} / \mathrm{ml}$. Following the infection, hematocrite and parasitaemia of cows were monitored daily using the Buffy Coat Technique (BCT) and the parasites counted using the method of Paris et al. (1982).

Pig: two weeks after a complete checkup and treatment as previously stated, the pig was immunosuppressed twice with cyclophosphamide (Endoxan ${ }^{\circledR}$, $300 \mathrm{mg} / \mathrm{kg}$ ) at three days intervals before infection and twice at three days intervals after infection. Blood parasitaemia was assessed using the BCT before the intravenous and intraperitoneal infection with $0.9 \mathrm{ml}$ of mice infecting blood containing $64 \times 10^{6}$ parasites $/ \mathrm{ml}$ of the T. b. gambiense isolate $\mathrm{B} 4 / \mathrm{F} 303$. Following experimental infection, hematocrite and parasitaemia were monitored once every two (or three) days until 
day (D) 16 using the Buffy Coat Technique (BCT). From D16 onward, additional tests were carried out in addition to BCT: the Card Agglutination Test for Trypanosomiasis (CATT) and the mini-Anion Exchange Centrifugation Test (m-AECT) performed directly on blood (m-AECT-blood) or with an additional concentration step by using buffy coats (m-AECT-buffy-coat) because the parasitological techniques applied so far (BCT and xenodiagnosis with G.p.gambiensis) were negative. The sensitivity thresholds of m-AECT-blood and m-AECT-buffy-coat are of 50 and 10 tryp/ml respectively (Buscher et al., 2009; Camara et al., 2010).

\section{- Infection of flies}

On cows: after each parasitological evaluation on infected cow, separate batches of 20 males and females G. m. submorsitans were allowed to feed on the side of cows at time when parasitaemia were low (i.e. fall under threshold which is not easily detectable by the BCT) or undetectable by the BCT (Fig. 1a). The infecting meal was unique and unfed flies were eliminated. All meals were taken in the obscurity during approximately ten minutes.

On pig: after each parasitological evaluation on infected pig, separate batches of 20 males and females G. p. gambiensis and/or G. m. submorsitans were allowed to feed every two (or three) days on the abdomen of the infected pigs (Fig. 1b). Only G. p. gambiensis was used for that purpose until D16; from D16 onward, both tsetse species were used. All meals were taken in the obscurity during approximately ten minutes as stated for cows and the infective meal was unique. Animals were slaughtered after the experiment.

- Dissection of flies

Flies were dissected using the method of Yoni et al. (2005). Flies that took their infective meal on cows were dissected at D2 and D5 post infective meal. Those having their infective meal on pig were dis-

a

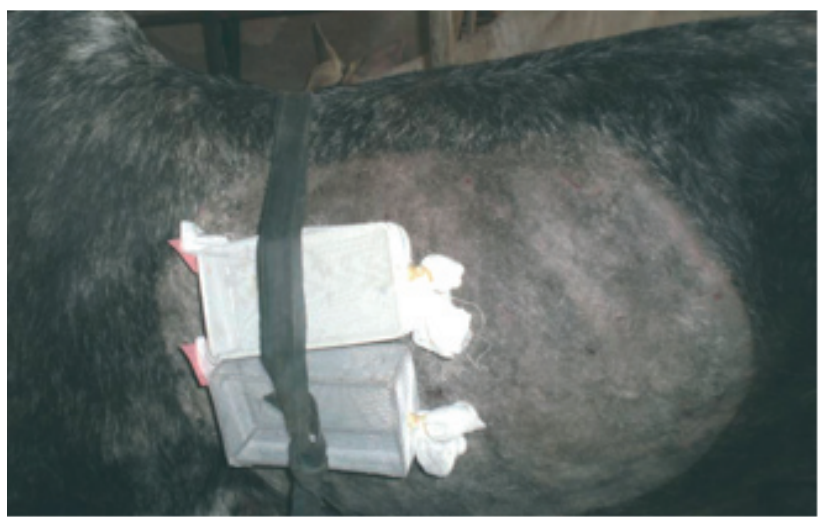

sected at D2 post infective meal only. They were dissected after approximately two-three minutes passage at freezing temperature. The midgut was examined by phase-contrast microscope (magnification $\times 400$ ) to locate and identify infections. Microscopic observation focused on the presence or absence of trypanosomes in the gut. In some cases an estimation of the number of trypanosomes present in the gut was made by examining the entire microscopic preparation.

\section{DATA ANALYSIS}

The Fisher's exact test was used to compare infection rates between males and females at different days post infection.

\section{RESULTS}

\section{EXPERIMENTAL INFECTIONS ON COWS INFECTED WITH T. CONGOLENSE}

$\checkmark$ igure 2 shows the evolution of parasitaemia in cows throughout the experimental period. A peak of parasitaemia was observed at around D16 post infection in both cows. Parasitaemia levels decreased thereafter to low levels in both animals with sporadic peaks observed in one of the cow toward the end of the experiment. This enabled us to feed flies on these animals at different parasitaemia levels.

Infection rates obtained by dissection of flies at two and five days post infective blood meal (PI) are shown in Table I. A total of 372 flies (G. m. submorsitans), including 189 females and 183 males were dissected. A total of 52 females and 42 males were found positive of which 50 and 40 were positive at D2 for females and males respectively. The percentage of infected flies at D2 PI is high (> $50 \%$ ) when parasitaemia in cows are greater than 1 parasite for 120 microscopic fields.

$\mathrm{b}$

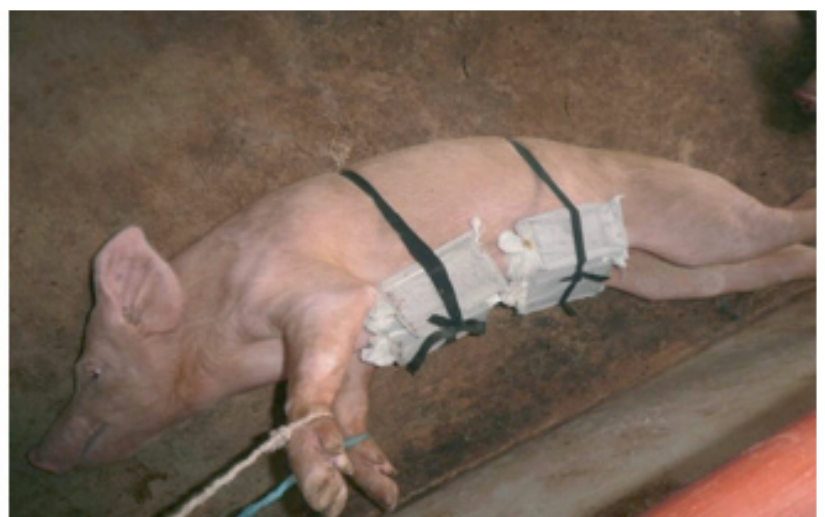

Fig. 1. - Tsetse flies from the CIRDES colonies fed on a cow (a) and on a pig (b). 


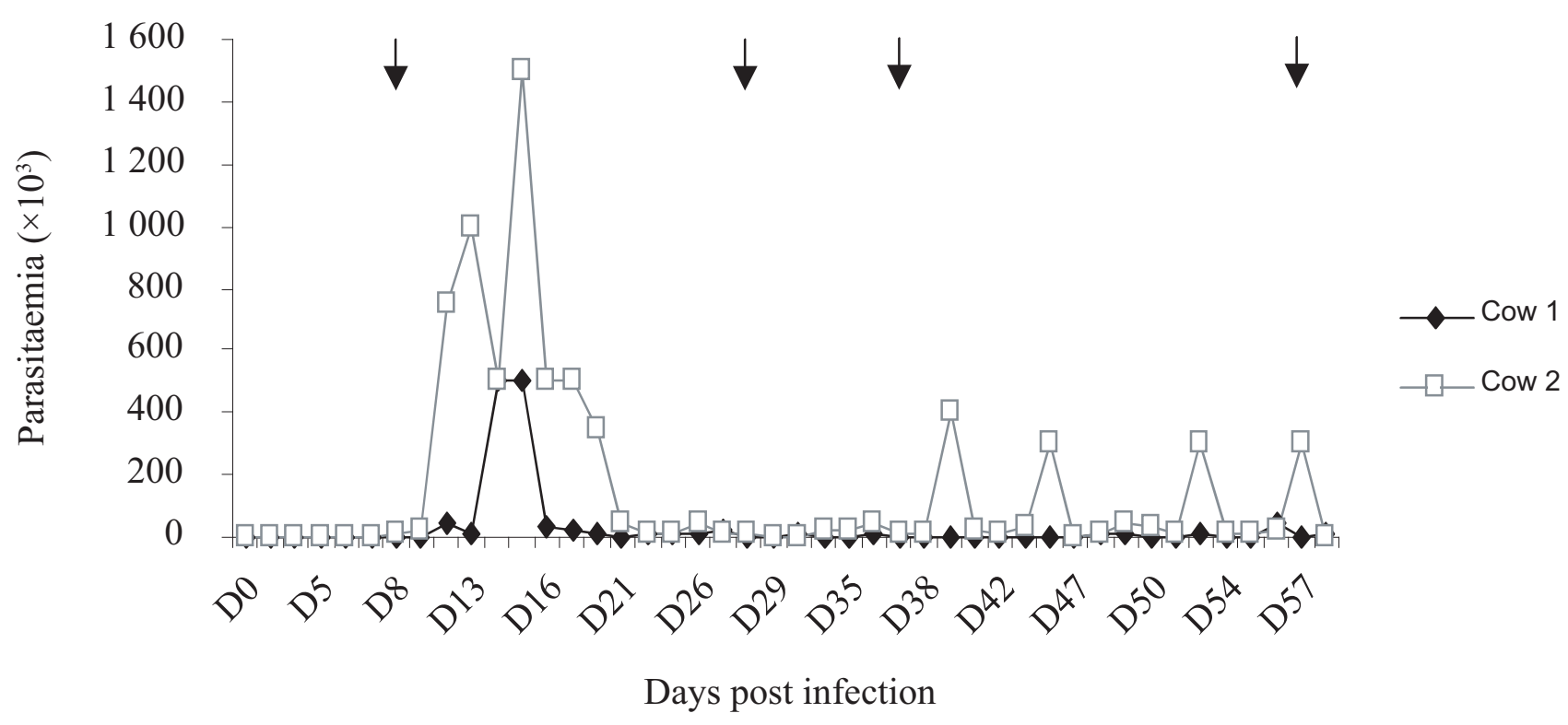

Fig. 2. - Infection profiles in the cows infected experimentally by T. congolense.

Arrows indicate the time at which xenodiagnosis was performed with G. m. submorsitans on infected animals.

\begin{tabular}{|c|c|c|c|c|c|c|c|c|c|c|}
\hline \multirow{2}{*}{$\begin{array}{l}\text { Blood } \\
\text { parasitaemia }\end{array}$} & \multicolumn{2}{|c|}{$2 \operatorname{Tryp}^{1} /$ field } & \multicolumn{2}{|c|}{5 Tryp/40 fields } & \multicolumn{2}{|c|}{1 Tryp/80 fields } & \multicolumn{2}{|c|}{1 Tryp/120 fields } & \multicolumn{2}{|c|}{1 Tryp/160 fields } \\
\hline & D2 & D5 & D2 & D5 & D2 & D5 & D2 & D5 & D2 & D5 \\
\hline $\mathrm{NDF}^{3}$ & 19 & 18 & 20 & 17 & 18 & 18 & 20 & 20 & 20 & 19 \\
\hline $\mathrm{NDM}^{4}$ & 19 & 18 & 20 & 20 & 15 & 16 & 20 & 19 & 18 & 18 \\
\hline $\mathrm{NPF}^{5}$ & 16 & 1 & 19 & 1 & 10 & 0 & 0 & 0 & 5 & 0 \\
\hline $\mathrm{NPM}^{6}$ & 14 & 0 & 11 & 1 & 12 & 1 & 0 & 0 & 3 & 0 \\
\hline$\% \mathrm{PF}^{7}$ & 84.2 & 5.6 & 95.0 & 5.9 & 55.6 & 0.0 & 0.0 & 0.0 & 25.0 & 0.0 \\
\hline$\% \mathrm{PM}^{8}$ & 73.7 & 0.0 & 55.0 & 5.0 & 80.0 & 6.3 & 0.0 & 0.0 & 16.6 & 0.0 \\
\hline
\end{tabular}

${ }^{1}$ Tryp: trypanosome; ${ }^{2}$ DPI: days post infective meal; ${ }^{3}$ NDF : number of dissected female; ${ }^{4}$ NDM: number of dissected males; ${ }^{5}$ NPF: number of positive females; ${ }^{6} \mathrm{NPM}$ : number of positive males; ${ }^{7} \mathrm{PF}$ : positive females; ${ }^{8} \mathrm{PM}$ : positive males.

Table I. - Results of xenodiagnosis with G. m. submorsitans fed on cows infected with T. congolense at different parasitaemia.

\section{Xenodiagnosis results}

\begin{tabular}{|c|c|c|c|c|c|c|c|c|c|c|c|}
\hline \multirow[b]{3}{*}{ Days PI ${ }^{1}$} & \multicolumn{4}{|c|}{ Number of dissected flies } & \multicolumn{4}{|c|}{ Number of infected flies } & \multirow{2}{*}{\multicolumn{3}{|c|}{$\begin{array}{c}\text { Serological and } \\
\text { parasitological diagnosis }\end{array}$}} \\
\hline & \multicolumn{2}{|c|}{$\mathbf{G p g}^{2}$} & \multicolumn{2}{|c|}{$\mathbf{G m s}^{3}$} & \multicolumn{2}{|c|}{ Gpg } & \multicolumn{2}{|c|}{ Gms } & & & \\
\hline & $\mathbf{F}^{4}$ & $\mathbf{M}^{5}$ & $\mathbf{F}$ & $\mathbf{M}$ & $\mathbf{F}$ & $\mathbf{M}$ & $\mathbf{F}$ & $\mathbf{M}$ & BCT & CATT & m-AECT \\
\hline D2-D14 & 108 & 105 & nd $^{6}$ & nd & 0 & 0 & nd & nd & - & nd & nd \\
\hline D16 & 18 & 16 & 0 & 0 & 0 & 0 & nd & nd & - & ++ & + \\
\hline D19 & 13 & 17 & 18 & 19 & 0 & 0 & 0 & 4 & - & nd & nd \\
\hline D39 & 19 & 12 & 19 & 17 & 0 & 0 & 0 & 3 & - & nd & + \\
\hline
\end{tabular}

${ }^{1}$ PI: post infection; ${ }^{2}$ Gpg: Glossina palpalis gambiensis; ${ }^{3} \mathrm{Gms}$ : Glossina morsitans submorsitans; ${ }^{4} \mathrm{~F}$ : female; ${ }^{5} \mathrm{M}:$ male; ${ }^{6}$ nd: not done.

Table II. - Results of xenodiagnosis with G. m. submorsitans and G.p. gambiensis on the infected pig with T. b. gambiense. Results of the serological and parasitological tests performed on the animal are also shown on the right part of the table. 
This corresponds to a parasitaemia of 333 tryp $/ \mathrm{ml}$ according to Paris et al. (1982). Below this parasitemic threshold the percentage of infected tsetse becomes lower, though still positive (25\% and $16 \%$ at D2). In contrast, tsetse infection rate is very low or nil at D5 PI whatever the parasitaemia level. At all blood parasitaemia tested, the percentage of infected females at D2 is not different from that of infected males $(\mathrm{p}>0.3)$, except at blood parasitaemia of 5 trypanosomes/40 fields where the percentage of infected females was significantly higher than males $(\mathrm{p}=0.008)$.

\section{EXPERIMENTAL INFECTION ON PIG INFECTED WITH T. B. GAMBIENSE}

During this experiment, 381 flies (308 G. p. gambiensis and 73 G. m. submorsitans) took their blood meal on the infected pig. Results of both parasitological tests performed on the animal and infection rates obtained in tsetse flies dissected at D2 PI are shown in Table II. Throughout the experiment no trypanosomes were detected by the BCT, however at D16 the pig was found positive by m-AECT-buffy-coat (one trypanosome in the collector tube) indicating a low parasitaemia in this animal of around 10 tryp/ml which correspond to the sensitivity threshold of the test. Furthermore, the CATT serological test was positive indicating that the animal harbored antibodies directed against trypanosome antigens. At this stage none of the G.p. gambiensis flies were found positive by xenodiagnosis. Because we suspected that flies from the G. p. gambiensis colony at CIRDES may have somehow lost part of their vectorial competence, we also used G. m. submorsitans in further xenodiagnosis experiments. Xenodiagnosis was positive at D19 PI with G. m. submorsitans flies (four positive out of 37 dissected) whereas G. p. gambiensis flies remained negative. To confirm the difference observed between the two species of tsetse at D19, we repeated the test at D39. At this stage the pig was still negative with the BCT test but remained positive with m-AECTblood (two trypanosomes observed in the collector tube) and m-AECT-buffy-coat (six trypanosomes in the collector tube) indicating that the animal had maintained a low parasitaemia level that can be estimated around 50 and $100 \mathrm{tryp} / \mathrm{ml}$ of blood according to the sensitivity thresholds of the tests. In agreement with the result obtained at D19, all G. p. gambiensis flies $(0 / 31$ dissected) were negative whereas trypanosomes were found in the midgut of three out of the 36 G. $m$ submorsitans flies dissected at D2 PI.

\section{COMPARISON OF PARASITAEMIA \\ IN THE MAMMALIAN HOST AND IN THE TSETSE FLY}

In order to assess the number of trypanosomes present in the infected flies that took their infective blood meal on pig at D39, the whole midgut microscopic preparation was examined and trypanosomes were counted. At least ten trypanosomes were found in each of the infected G. m. submorsitans flies. Weighting the flies before and after the blood meal then enabled us to estimate the quantity of blood taken by the flies. We found that flies had taken in average $\sim 10 \mu$ l of blood. Thus the parasitaemia in the blood meal of infected flies can be estimated to be around 10 trypanosomes per $10 \mu \mathrm{l}$ of blood, hence $1,000 \mathrm{tryp} / \mathrm{ml}$. This is in deep contrast with our evaluation of the blood parasitaemia in the pig (50-100 tryp/ml, see above).

\section{DISCUSSION}

X enodiagonosis, in which the natural vector is fed on the patient, or in which infected tissues are injected into a recipient susceptible host, has for long been used to increase the sensitivity of parasite detection in infected hosts. Triatomine bugs have been widely used for the diagnosis of Chagas disease and xenodiagnosis is still considered as the gold standard for parasitological diagnosis (Avilla et al., 1993). Among trypanosomatids, xenodiagnosis was also shown to be efficient for the diagnosis of Leishmania braziliensis and Leishmania infantum infections (Rojas et al., 1989; Molina et al., 1996). In HAT, some old attempts were also made with tsetse flies to confirm serological suspects. The use of xenodiagnosis was found to be successful in Congo (Frezil, 1971) whereas negative results were obtained in Mali (Challier, 1972, 1973). To our knowledge, no other attempts were made since then, in part because of the challenge of rearing or maintaining tsetse flies in field conditions. Nevertheless experimental studies on cattle infected by $T$. congolense or $T$. b. brucei s.l. have shown that tsetse flies could get infected even in the chronic phase of infection, at times when blood parasitaemia could not be detected by microscopic examination (Mihok et al., 1991; Van Den Bossche et al., 2005; Akoda et al., 2008). Thus data exist suggesting that xenodiagnosis in HAT could represent a highly sensitive tool to detect trypanosomes.

\section{EXPERIMENTAL INFECTION IN CATTLE}

In this first experiment we wanted to assess if the tsetse colonies reared at the CIRDES could be used for xenodiagnosis purposes (i.e. if they were still able to get infected upon feeding on experimentally infected animals). For this purpose we chose a well known model of cattle infection with $T$. congolense and used teneral G. m. submorsitans for the xenodiagnosis procedures. In the two crossbred cows, the infection pattern was characterized by a first pick of parasitaemia 
(corresponding to the acute phase) followed by a chronic phase in which parasite blood concentrations decreased to sometime very low levels. This situation enabled us to test the efficiency of xenodiagnosis at different parasitaemia levels and to determine at what time post infective blood meal flies should be dissected for xenodiagnosis to be optimum. At high blood parasitaemia levels ( $\geq 1$ trypanosome observed/80 microscopic fields) midgut infection rates were high in both male and female when tsetse flies were dissected at D2 post infective meal. In sharp contrast very few flies were found positive at D 5 post infective meal, suggesting that the majority of trypanosomes (at the exception of those able to establish an infection) are killed at that time in the gut, probably by the fly immune system (Gibson \& Bailey, 2003; Haines et al., 2010). Anyhow, our results indicate that the optimum day post infective blood meal is D2 because in addition, microscopic examination at D0 or D1 is impaired by the presence of numerous red blood cells in the fly gut (data not shown). The percentage of infected flies at D2 post infective meal decreased sharply below the threshold of 1 trypanosome/80 microscopic fields observed in the blood of the animal. However at the lowest parasitaemia tested (1 trypanosome/160 microscopic fields, corresponding to a parasitaemia of $250 \mathrm{tryp} / \mathrm{ml}$ of blood), 16,6 and $25 \%$ of G. m. submorsitans male and female respectively were still positive (Table I).

These results suggest that at low parasitaemia levels, efficacy seems to be independent of the parasite concentration as reflected by the fact that flies were found infected on cattle harbouring parasitaemia of 1 trypanosome/160 fields but not when they were fed on cattle at 1 trypanosome/120 fields. An alternative explanation is also that at such low parasitaemia level accurate parasite concentration are difficult to obtain with the method of Paris et al. (1982). It is noteworthy that in the context of xenodiagnosis, a single infected fly is sufficient to make the test positive. Therefore an adequate number of flies (20 flies, assuming an infection rate of $5 \%$ ) are required to maximize the probability to find an infected fly when they are fed on hosts with low blood parasitaemia. Either male or female can be used for this purpose since no difference of infection rates were observed between sexes.

\section{EXPERIMENTAL INFECTION IN PIGS}

In order to further test the sensitivity of xenodiagnosis in conditions that are closer to the situation encountered in the human disease (sleeping sickness or HAT), we then used a pig, a known natural reservoir of T. b. gambiense (Mehlitz et al., 1986; Penchenier et $a l ., 2005)$ that we infected with a field isolate of $T . b$. gambiense recently isolated in West Africa. We then used flies from the G.p. gambiensis colony at CIRDES for xenodiagnosis purposes. Interestingly, the pattern of infection in the pig was similar to what is observed in HAT endemic areas on seropositive subjects that are negative to parasitological tests but may sometimes be positive by PCR (Solano et al., 2002; Jamonneau et al., 2004; Koffi et al., 2006; Kaboré et al., 2011).

Throughout the experiment, no trypanosomes could be detected in the pig blood by the BCT technique although we showed that the animal had developed a positive response to the CATT by D16. From this time point we thus chose to use m-AECT, the most sensitive parasitological method (Busher et al., 2009; Camara et al., 2010) to assess the parasitological status of the pig. The pig tested positive to M-AECT on D16 and D39, but with only very few trypanosomes observed in the collector. This indicated that the parasite blood concentration was close to the test detection limit, giving an estimation of the pig parasitaemia in the range of $10-50$ and $50-100$ tryp/ $\mathrm{ml}$ of blood at D16 and D39 respectively. Whereas none of the G. p. gambiensis flies fed on the animal were found infected throughout the experiment, four out of 37 and three out of 36 flies were found infected when G. m. submorsitans was used for xenodiagnosis at D19 and D39 respectively. The observed difference of xenodiagnosis efficiency between G. m. submorsitans and G. p. gambiensis suggests that the G.p.gambiensis colony at CIRDES has somehow lost its vectorial competence, although further experiments will be required to further explore this point. Nevertheless they also indicate that the G. $m$. submorsitans colony at CIRDES can be used for both the xenodiagnosis of $T$. congolense and $T$. $b$. gambiense infections even at low blood parasitaemia in the infected hosts.

\section{DIFFERENCES OF PARASITEMIA \\ BETWEEN TSETSE AND PIGS: CO-EVOLUTION?}

An intriguing observation made in the frame of this study was that the number of trypanosomes present in the gut of G. m. submorsitans infected flies was at least ten times higher than the estimated blood parasitaemia. Several hypotheses may explain this observation. A first possibility is that the measured peripheral blood parasitaemia is not representative of the parasitaemia encountered by the tsetse at the skin biting site. An explanation could be that the parasitaemia is higher in capillary blood and/or that additional trypanosomes coming from lymph vessels are present at the biting site. Another hypothesis is that some Glossina saliva components, delivered during the blood meal, may act as attractants concentrating trypanosomes at the biting site to increase parasite transmission probability. 
Regarding this hypothesis, it is interesting to note that increasing data point out to the fact that tsetse saliva is targeted by trypanosomes to increase their transmission probabilities. Recently, Van Den Abbeele et al. (2010) have suggested that trypanosomes have the ability to modify the tsetse saliva composition in a way that alters the fly feeding behaviour to favour parasite transmission. Finally, a last hypothesis is that the few blood stream forms of trypanosomes ingested during the blood meal may undergo a multiplication cycle before entering into procyclic differentiation. This is turn could help the parasite passing through the self cure process that seems to occur in the fly after D2 post infective meal. Further work is now required, in which the blood parasitaemia and the fly parasitaemia throughout the infection process, will need to be measured more accurately to better characterize this aspect of the trypanosome life-cycle. Real time quantitative PCR methods could be used for this purpose.

\section{CONCLUSION}

These preliminary results indicate that xenodiagnosis of $T . b$. gambiense HAT using the G. $m$. submorsitans colony at CIRDES is technically feasible. According to the results obtained in the frame of this study, we propose the following protocol: i) feeding of a batch of 20 teneral G. $m$ submorsitans aged 72 hours; ii) dissection of flies and examination of the midgut two days after the blood meal with an ordinary microscope (magnification $\times 400$ ). Although the use of xenodiagnosis is unlikely to be widely applicable for HAT diagnosis, it could be of great help to better characterize the parasitological status of unconfirmed serological suspects and to assess their role in transmission. Indeed these subjects constitute a non negligible proportion of the population in endemic areas (Bucheton et al., 2011). Although they are suspected to be infected at very low parasitaemia levels, there is yet no direct evidence that this is indeed the case.

\section{ACKNOWLEDGEMENTS}

VUTe thank the coordinator of the International Master in Medical and Veterinary Entomology (MIE), the direction of CIRDES, the team of the CIRDES insectarium, and L. Millogo, Y. Mémé and H. Sakandé for their technical help in this work.

\section{REFERENCES}

Akoda K., Harouna S., Marcotty T., De Deken R. \& Van den Bossche P. Investigations on the transmissibility of Trypanosoma congolense by the tsetse fly Glossina morsitans morsitans during its development in a mammalian host. Acta Tropica, 2008, 107, 17-19.

Avilla H.A., Pereira J.B., Thiemann O., De Paiva E., Degrave W., Morel C.M. \& Simpson L. Detection of Trypanosoma cruzi in blood specimens of chronic chagasic patients by polymerase chain reaction amplification of kinetoplast minicircle DNA: Comparison with serology and xenodiagnosis. Journal of Clinical Microbiology, 1993, 31, 2421-2426.

Büscher P., Mumba Ngoy D., Kaboré J., Lejon V., Robays J., Jamonneau V., Bebronne N., Van der Veken W. \& Biéler S. Improved models of Mini Anion Exchange Centrifugation Technique (m-AECT) and Modified Single Centrifugation (MSC) for sleeping sickness diagnosis and staging. PLoS NTD, 2009, 3, e471.

Bucheton B., Macleod A. \& Jamonneau V. Human host determinants influencing the outcome of $T . b$. gambiense infections. Parasite Immunology, 2011, 33, 438-447.

Camara M., Camara O., Ilboudo H., Sakande H., Kaboré J., N'Dri L., Jamonneau V. \& Bucheton B. Sleeping sickness diagnosis: use of Buffy Coat improves the sensitivity of the mini anion exchange centrifugation test. Tropical Medicine \& International Health, 2010, 15, 796-799.

Challier A. Essais de xénodiagnostic sur des suspects immunologiques (IgM) de trypanosomiase humaine à Trypanosoma gambiense à l'aide de Glossina palpalis gambiensis, en Afrique occidentale. Rapport Mission ORSTOM auprès de l'OCCGE, 1972, No 23/Ent.72.

Challier A \& Bicaba A. Essais de xénodiagnostic sur des suspects immunologiques (IgM) de trypanosomiase humaine à Trypanosoma gambiense Dutton à l'aide de Glossina palpalis gambiensis Vanderplank 1949, en Afrique occidentale ( $2^{\text {ème }}$ série d'essais). Rapport Mission ORSTOM auprès de l'OCCGE, 1973, N 26/Ent.73.

FrézIL J.L. Application du xénodiagnostic dans le dépistage de la trypanosomiase à $T$. gambiense chez des sujets immunologiquement suspects. Bulletin de la Société de Pathologie Exotique, 1971, 64, 871-878.

Geiger A., Ravel S., Mateille T., Janelle J., Patrel D., Cuny G. \& FruTOS R. Vector competence of Glossina palpalis gambiensis for Trypanosoma brucei s.l. and genetic diversity of the symbiont Sodalis glossinidius. Molecular Biology and Evolution, 2007, 24, 102-109.

Gibson W. \& BAILEY M. The development of Trypanosoma bruce $i$ within the tsetse fly midgut observed using green fluorescent trypanosomes. Kinetoplastid Biology and Disease, 2003, 2, 1-13.

Haines L.R., Lehane S.M., Pearson T.W. \& Lehane M.J. Tsetse EP protein protects the fly midgut from trypanosome establishment. PLoS Pathog, 2010, 6 (3), e1000793.

Herbert W.J. \& Lumsden W.H.R. Trypanosoma brucei: A rapid "matching" method for estimating the host's parasitemia. Experimental Parasitology, 1976, 40, 427-431. 
Jamonneau V., Solano P., Koffi M., Denizot M. \& Cuny G. Apports et limites du diagnostic de la trypanosomiase humaine africaine. Médecine/Sciences, 2004, 20, 871-875.

Jannin J., Moulia-Pelat J.P., Chanfreau B., Penchenier L., Louis J.P., Nzaba P., De La Baume F.E., Eozenou P. \& Cattand P. Trypanosomiase humaine africaine : étude d'un score de présomption de diagnostic au Congo. Bulletin World Health Organisation, 1993, 71, 215-222.

Kaboré J., Koffi M., Bucheton B., Macleod A., Duffy C., Ilboudo H., Camara M., De Meeûs T., Belem A.M.G. \& JAMONNEAU V. First evidence that parasite infecting apparent aparasitemic serological suspects in human African trypanosomiasis are Trypanosoma brucei gambiense and are similar to those found in patients. IGE, 2011, 6, 1250-1255.

Koffi M., Solano P., Denizot M., Courtin D., Garcia A., Lejon V., Büscher P., Cuny G. \& Jamonneau V. Aparasitemic serological suspects in Trypanosoma brucei gambiense human African trypanosomiasis: A potential human reservoir of parasites? Acta Tropica, 2006, 98, 183-188.

Mehutz D. Le reservoir animal de la maladie du sommeil à Trypanosoma brucei gambiense. Études et synthèses de l'IEMVT 18, Maisons-Alfort, 1986, 156 p.

Minok S., Olubayo R.O. \& Wesong D.F. Infection rates in Glossina morsitans morsitans fed on waterbuck and Boran cattle infected with Trypanosoma congolense. Acta Tropica, 1991, 49, 185-191.

Molina R. \& Alvar J. A simple protocole for the indirect xenodiagnosis of Leishmania infantum in the blood of HIV-infected patients. Annals of Tropical Medicine and Parasitology, 1996, 90, 639-640.

PARIS J., MurraY M. \& MCODIMBA F. A comparative evaluation of the parasitological techniques currently available for the diagnosis of the African trypanosomiasis in cattle. Acta Tropica, 1982, 39, 307-316.

Penchenier L., Alhadji D., Bahébégué S., Simo G., Laveissière C. \& Cuny G. Spontaneous cure of domestic pigs experimentally infected by Trypanosoma brucei gambiense. Implications for the control of sleeping sickness. Veterinary Parasitology, 2005, 133, 7-11.

Rojas E., Scorza E. \& Scorza J.V. Xenodiagnostico con Lutzomyia youngi en casos venezolanos de Leishmaniasis. Memórias do Instituto Oswaldo Cruz, 1989, 84, 29-34.

Solano P., Jamonneau V., N'Guessan P., N'Dri L., Dje N.N., Miezan T.W., Lejon V., Büscher P. \& Garcia A. Comparison of different DNA preparation protocols for PCR diagnosis of human trypanosomiasis. Acta Tropica, 2002, $82,349-356$.

Van Den Abbeele J., Caljon G., De Ridder K., De Baetselier P. \& Coosemans M. Trypanosoma brucei modifies the tsetse salivary composition, altering the fly feeding behavior that favors parasite transmission. PLoS Pathog, 2010, 6 (6), e1000926.

Van den Bossche P., Ky-Zerbo A., Brandt J., Marcotty T., GeerTs S. \& De Deken R. Transmissibility of Trypanosoma brucei during its development in cattle. Tropical Medicine and International Health, 2005, 10 (9), 833-839.

Walshe D.P., OoI C.P., Lehane M.J. \& Haines L.R. The enemy within: Interactions between tsetse, trypanosomes and symbionts. Advances in Insect Physiology, 2009, 37, 119175.

Yoni W., Bila C., Bouyer J., Desquesnes M. \& Kaboré I. La dissection des glossines ou mouches tsé-tsé. Santé animale en Afrique de l'Ouest, 2005, Fiche № 23.

Received on May $17^{\text {th }}, 2011$ Accepted on September $13^{\text {th }}, 2011$ 